\title{
Klinefelter sendromlu ve normal karyotipli hastaların testiküler sperm ekstraksiyonu sonuçlarının karșılaștılması: 10 yıllık tek merkez deneyimi
}

\author{
Comparison of testicular sperm extraction results in patients with \\ klinefelter syndrome and normal karyotypes: 10 years single center \\ experience
}

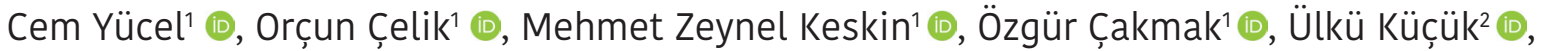 \\ Zafer Kozacıoğlu' (1)
}

\section{öz}

AMAC̦: Klinefelter sendromlu (KS) ve normal karyotipli (46XY) nonobstrüktif azospermili (NOA) hastalarda mikroskopik testiküler sperm ekstraksiyonu (mTESE) sonuçlarını karşılaştırarak KS’nin mTESE sonuçlarına etkilerini ortaya koymak.

GEREÇ ve YÖNTEMLER: Kurumumuzda mTESE operasyonu olan hastaların medikal verilerini retrospektif olarak inceledik. Hastalar, genetik sonuçlarına göre normal karyotipli (grup 1) ve KS’li (grup 2) olarak iki gruba ayrıldı. Bu iki grup yaş, infertilite süresi, hormon profili, mTESE'de sperm elde etme oranı ve testiküler histopatolojilerine göre karşılaştırıldı.

BULGULAR: Çalıșmaya 413 hasta dahil edildi. Bu hastaların yaș orta-

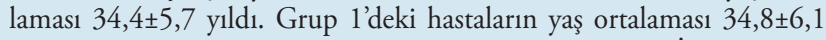
yıl, grup 2'deki hastaların yaş ortalaması $30,8 \pm 4,8$ yıldı. İki grup arasında hasta yaşı açısından istatistiksel anlamlı farklılık yoktu $(\mathrm{p}=0,098)$. Testosteron düzeyi ve sperm elde etme oranı grup 1'de grup 2'ye göre istatistiksel olarak anlamlı yüksekti. Foliküler uyarıcı hormon düzeyi, luteinizan hormon düzeyi grup 2'de grup 1'e göre istatistiksel anlamlı yüksekti. İnfertilite süresi, östradiol düzeyi ve prolaktin düzeyi açısından gruplar arasında istatistiksel anlamlı farklılık saptanmadı.

SONUÇ: KS'li hastalarda mTESE başarısının normal karyotipli hastalara göre daha düşük olduğu gözlendi.

Anahtar Kelimeler: Klinefelter sendromu; azospermi; testiküler sperm ekstraksiyonu; infertilite

\section{ABSTRACT}

OBJECTIVE: We aimed to compare the results of microscopic testicular sperm extraction (mTESE) with Klinefelter syndrome (KS) and normal karyotype nonobstructive azoospermia (NOA) patients to determine the effects of KS on mTESE results.

MATERIAL and METHODS: We retrospectively reviewed the medical data of patients with the diagnosis of NOA who had undergone the mTESE operation in our institution. According to the genetic results, patients were divided into two groups with normal karyotype (group 1) and KS (group 2). These two groups were compared according to age, duration of infertility, hormone profile, sperm retrieval rate and testicular histopathology.

RESULTS: In this study, 413 patients were included. The mean age of these patients is $34.4 \pm 5.7$ years. The mean age of the patients in group 1 was $34.8 \pm 6.1$ years, and in group 2 was $30.8 \pm 4.8$ years. There was no statistically significant difference in age between the two groups $(\mathrm{p}=0.098)$. Testosterone level and sperm retrieval rate were statistically higher in group 1 than in group 2. Follicular stimulating hormone level and luteinizing hormone level were statistically higher in group 2 than in group 1 . There was no statistically significant difference between groups in terms of duration of infertility, estradiol level and prolactin level.

CONCLUSION: In patients with KS, mTESE success was observed to be lower than in patients with normal karyotype.

Keywords: Klinefelter syndrome; azoospermia; testicular sperm extraction; infertility
${ }^{1}$ Tepecik Eğitim ve Araştırma Hastanesi, Üroloji Kliniği, Izmir ${ }^{2}$ Tepecik Eğitim ve Araştırma Hastanesi, Patoloji Kliniği, İzmir

\section{Yazışma Adresi/ Correspondence:}

Uzm. Dr. Cem Yücel

Yenișehir Mah, Gaziler Cad. No: 468, 35100 Konak/Izmir, Türkiye

Tel.

E-mail: meclecuy@hotmail.com

Geliş/ Received: 21.01.2018

Kabul/ Accepted: $\quad 07.02 .2018$

\section{Gíriș}

Klinefelter sendromu (KS) erkeklerde fazladan bir X kromozomunun olmasıyla karakterize en sık görülen seks kromozom bozukluğu olup yenidoğan erkek bebeklerdeki prevalansı 1:500 ile 1:700 aralığında olduğu bilinmektedir. ${ }^{[1]}$ İlk kez 1942 yılında uzun vücut yapısı, dişi vücut fenotipi, jinekomasti, küçük testisler ve infertilite semptomlarından oluşan bir sendrom olarak tanımlanmıştır. ${ }^{[2]} \mathrm{KS}$, infertil 
hastaların \%3, azospermik hastaların ise \%11,9'inde görülmektedir. ${ }^{[3]}$ Non-mozaik (47, XXY) veya mozaik formda (47, XXY/46, XY) görülebilir. KS’li hastalar \%85 non-mozaik forma sahiptir. Mozaik forma sahip hastaların ejakülatlarında sperm bulunmasına rağmen non-mozaik forma sahip hastalar sıklıkla steril olmaktadır. KS'li hastalarda testiküler dejenerasyon fetal hayatta başlayıp, infant ve puberte dönemlerinde devam edip, erişkin yaşta azospermiye yol açacak kadar testiküler dokuda bozulmaya yol açabilmektedir. ${ }^{[4]} \mathrm{Bu}$ hastaların testislerindeki bozulmaya rağmen fokal alanlarda spermatogenez görülebilmektedir. Mikroskopik testiküler sperm ekstraksiyonu (mTESE) ve intrastoplasmik sperm enjeksiyon (ICSI) yöntemleriyle, bu hastaların kendi çocuklarına biyolojik baba olmaları sağlanabilmektedir. ${ }^{[5]} \mathrm{KS}$ 'li hastalarda mTESE'de sperm elde etme oranları literatürde \%16 ile \%60 aralığındadır. ${ }^{[6]}$ Bu çalışmanın amacı KS'li ve normal karyotipli nonobstrüktif azospermili (NOA) hastalarda mTESE sonuçlarını karşılaştırarak KS’nin mTESE sonuçlarına etkilerini ortaya koymaktır.

\section{GEREC VE YöNTEM}

\section{Çalıșma dizaynı ve hastalar}

Kurumumuzda 2008 ile 2018 yılları arasında NOA tanılı hastalarda yapılan mTESE operasyonlarının tıbbi verileri retrospektif olarak gözden geçirildi. NOA tanısı klinik bulgular, medikal hikaye, fizik muayene, serum hormon düzeyleri, genetik analiz ve Dünya Sağlık Örgütü'nün önerdiği gibi, iki semen analizi ile doğrulandı. Semen analizleri 3-4 günlük cinsel perhiz sonrası elde edildi. Tüm hastaların serum testosteron (T), foliküler uyarıcı hormon (FSH), luteinizan hormon (LH), östradiol (E2), prolaktin (PRL) ve genetik analiz (karyotip analizi ve Y kromozomu mikrodelesyon analizi) sonuçları değerlendirildi. Hormon profili için hastalardan sekiz saatlik açlık sonrasında antekubital venden kan alındı. Hormon analizi, Roche Cobas e601 HITACHI cihazı yardımıyla mikropartikül enzim immunoassay yöntemiyle yapıldı. Kromozom analizi için hastalara ait periferik venöz kan örneklerine 72 saatlik fitohemaglütinin ile indüklenmiş hücre kültürü uygulandı. Takiben, konvansiyonel sitogenetik yöntemler kullanılarak 47 XXY karyotip varlığı araştırıldı. Kliniğimizde mTESE operasyonu öncesi $\mathrm{Y}$ kromozom mikrodelesyon analizi tüm hastalara yapılıp AZFa ve AZFb mikrodelesyonu olan hastalara mTESE önerilmemektedir. Ek anomali olasılığını dışlamak amacıyla, tüm hastaların eksternal organlarının fizik muayenesi yapıldı. Çalışmaya 413 hasta dahil edildi. $\mathrm{Bu}$ hastalar genetik analiz sonuçlarına göre non-mozaik KS olan (47XXY) ve normal karyotipli (46 XY) olan hastalar olarak iki gruba ayrıldı. Bu gruplar, yaş, infertilite süresi, hormon profili, mTESE'de sperm elde etme oranlarına ve testis biyopsisi histopatolojik sonuçlarına göre karşılaştırıldı. Non-mozaik KS dışında genetik anamolisi olan, vazektomi hikayesi olan, testiküler travma hikayesi olan, malign hastalık hikayesi olan, azospermisi obstrüktif bir sebebe bağlı olan ve birden fazla mTESE operasyonu olan hastalar çalışmadan dışlandı.

\section{mTESE tekniği}

mTESE operasyonunun planlandığı gün ek bir semen örneği daha alınıp, spermatozoa olmadığı doğrulandı. mTESE operasyonu öncesi tüm hastalara bilgilendirilmiş onam formu imzalatıldı. Tüm hastalar mTESE operasyonunu spinal anestezi ile oldular. Raphe skrotumdan orta hat vertikal insizyon yapılıp, skrotal katlar geçilip büyük testise ulaşıldı. Tunika vajinalis açıldı ve testisi çevreleyen tunika albuginea vizüelize edildi. Bu aşamadan sonra, operasyon $20 \mathrm{x}$ büyütmeli operasyon mikroskobu altında gerçekleştirildi. Schlegel ve ark.'nın tarif ettiği gibi, tunika albugineayada antimezenterik alandan avasküler bir alan seçilerek ince bir bistüri ile 3 cm'lik bir kesi yapıldı. ${ }^{[7]}$ Testiküler parankim içindeki opak, büyük, beyaz tübüllerden küçük örnekler alındı. Her örnek, solüsyon ile dolu petri kabına konuldu. Tüm örnekler, hızlıca spermatoza varlığını araştırmak amacıyla embriyolog tarafından 200x büyütmeli mikroskop ile değerlendirildi. ICSI için uygun spermatozoa bulunduğunda, operasyon sonlandırıldı. İlk örneklerde spermatozoa saptanamadığında, aynı testisten ek örnekler yollandı. Büyük testisten yollanan örneklerde spermatozoa bulunamadığı durumlarda, karşı testisten de örnek yollandı.

\section{Histopatolojik analiz}

Testiküler histopatolojiyi belirlemek için, tüm testiküler biyopsi örnekleri Bouin solüsyonunda fikse edildikten sonra doku takip işleminin ardından parafin bloklara gömüldü ve $4 \mu \mathrm{m}$ kalınlığında kesitler alınıp hematoksilen ve eozin boyamanın ardından 400x büyütmeli mikroskop ile, patoloji uzmanı tarafından değerlendirildi. Her biyopsi örneği için en az 100 seminifer tübülün germinal epitelyumu değerlendirildi. Germinal epitelyum varlığı saptanan tüm biyopsi örneklerinin spermatogenez durumu Johnsen skoru (JS) kullanılarak belirlendi. JS'ye göre her tübül örneğinin germinal epitelyumuna doku matürasyonuna ve spermatogenez durumuna göre 1 ile 10 arasında puan verildi. Bu skorlama sisteminde; tübüler sklerozis 1 , sadece sertoli hücreleri 2 , sadece spermatogonia 3, primer spermatosit evresinde duraksama 4 veya 5 , erken spermatit evresinde duraksama 6 veya 7 , geç spermati evresinde duraksama 8 veya 9 , tam spermatogez 10 olarak skorland.$^{[8]}$ Her biyopsi örneği için ortalama JS 
hesaplandı. Testiküler biyopsi örneklerinin klasifikasyonu şu şekilde yapıldı: normal spermatogenez (NS) (ortalama JS; 10), hypospermatogenez (HS) (ortalama JS; 8-9), geç maturasyon duraksaması (LMA) (ortalama JS; 6-7), erken maturasyon duraksaması (EMA) (ortalama JS; 3-4-5), Sertoli cell only (SCO) (ortalama JS; 2), ve tübüllerin hiyalizasyonu (HT) (ortalama JS; 1).

\section{İstatistiksel analiz}

Değişkenlerin normal dağılıma uygunluğu Shapiro Wilk Testi ile sınandı. Kategorik değişkenler frekans ve yüzde, nümerik değişkenler ortalama ve standart sapma değerleri kullanılarak betimlendi. İki kategorik değişken arasındaki ilişki Ki-kare testi ile araştırıldı. İki bağımsız ortalama Student t Testi veya Mann-Whitney U Testi ile karşılaşt1rıldı. İkiden fazla bağımsız değişken ANOVA testi ile karşılaştırıldı. Veri analizleri SPSS versiyon 22.0 (SPSS Inc, Chicago, Illinois, USA) programı kullanılarak gerçekleştirildi ve $<0,05$ 'lik bir $\mathrm{p}$ değeri anlamlı kabul edildi.

\section{BULGULAR}

Çalışmaya 413 hasta dahil edildi. Bu hastalarda: ortalama

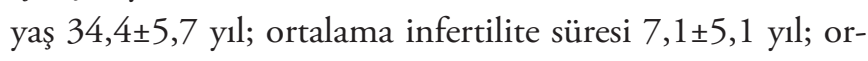
talama T düzeyi $373,1 \pm 186,2 \mathrm{ng} / \mathrm{dL}$; ortalama E2 düzeyi $26,3 \pm 12,4 \mathrm{pg} / \mathrm{mL}$; ortalama FSH düzeyi 22,6 $\pm 18,2 \mathrm{mIU} /$ $\mathrm{mL}$; ortalama LH düzeyi 9,8 $\pm 9,2 \mathrm{mIU} / \mathrm{mL}$; ortalama PRL düzeyi $10,8 \pm 5,7 \mathrm{ng} / \mathrm{mL}$ ve ortalama sperm elde etme oranı \%56,9 olarak saptandı. Çalışmaya dahil edilen hastalar karyotip analizi sonuçlarına göre iki gruba ayrıldı. Çalışmaya dahil edilen 413 hastanın 372'sinde normal karyotip (grup 1), 41 'inde non-mozaik KS (grup 2) saptand.. Grup 1'deki hastaların ortalama yaşı 34,8 $\pm 6,1$ yıl; grup 2'deki hastaların ortalama yaşı $30,8 \pm 4,8$ yıldı. Bu fark, istatistiksel olarak anlamlı değildi ( $\mathrm{p}=0,098)$. Grup 1'deki hastaların \%59,7 (222/372), grup 2'deki hastaların \%31,7 (13/41)'sinde mTESE'de spermatozoa elde edildi. İki grup arasında T düzeyi, FSH düzeyi, LH düzeyi, sperm elde etme oranı ve histopatoloji açısından istatistiksel anlamlı farklılık saptandı. İnfertilite süresi, E2 düzeyi ve PRL düzeyi açısından gruplar arasında istatistiksel anlamlı farklılık saptanmadı. İki grubun mTESE sonuçlarının karşılaştırılması Tablo 1'de özetlendi. KS'li hastalarda sperm elde etme oranları fibrotik histopatolojili hastalarda \%0 (0/14); SCO'lu hastalarda \%25 (2/8); EMA'lı hastalarda \%20 (1/5); LMA'lı hastalarda \%60 (6/10) ve HS'li hastalarda \%100 (4/4) olarak saptand. KS'li hastalarda, mTESE'de sperm elde edilebilen hastalarda ortalama $\mathrm{T}$ düzeyi $312,7 \pm 182,9 \mathrm{ng} / \mathrm{dL}$, sperm elde edilemeyen hastalarda 306,1 $\pm 197,8 \mathrm{ng} / \mathrm{dL}$ olarak bulundu.

\section{TARTIŞMA}

İnfertilite genel olarak üreme fonksiyonunun yerine getirilememesi olarak tanımlanır. Gebelikle ilgili herhangi bir koruma önlemi olmaksızın bir yıl düzenli cinsel ilişkiye rağmen çocuk sahibi olamayan çiftler için infertilite söz konusudur. İnfertilite oranı toplumda \%10-15 arasında görülmektedir. ${ }^{[9]}$ Bu çalışmada, bizim tek merkezimizde

Tablo 1. Normal Karyotipli ve Klinefelter Sendromlu hastaların karşılaştırılması

\begin{tabular}{|c|c|c|c|c|}
\hline & $\begin{array}{l}\text { Tüm Hastalar } \\
\qquad(n=413)\end{array}$ & $\begin{array}{l}\text { Normal karyotip } \\
\quad(n=372)\end{array}$ & $\begin{array}{c}\text { Klinefelter sendromu } \\
\qquad(n=41)\end{array}$ & $p$ değeri \\
\hline Yaş (yıl) & $34,4 \pm 5,7$ & $34,8 \pm 6,1$ & $30,8 \pm 4,8$ & 0,098 \\
\hline İnfertilite süresi (yıl) & $7,1 \pm 5,1$ & $7,3 \pm 4,7$ & $6,2 \pm 6,9$ & 0,126 \\
\hline SRR (\%) & 56,9 & 59,7 & 31,7 & $<0,01$ \\
\hline $\mathrm{T}(\mathrm{ng} / \mathrm{dL})$ & $373,1 \pm 186,2$ & $380,3 \pm 178,9$ & $308,2 \pm 191,3$ & $<0,01$ \\
\hline E2 (pg/mL) & $26,3 \pm 12,4$ & $28,3 \pm 13,8$ & $26,1 \pm 12,5$ & 0,682 \\
\hline $\mathrm{FSH}(\mathrm{mlU} / \mathrm{mL})$ & $22,6 \pm 18,2$ & $20,5 \pm 18,2$ & $42,1 \pm 18,4$ & $<0,01$ \\
\hline $\mathrm{LH}(\mathrm{mlU} / \mathrm{mL})$ & $9,8 \pm 9,2$ & $8,8 \pm 5,8$ & $19,3 \pm 10,1$ & $<0,01$ \\
\hline PRL (ng/mL) & $10,8 \pm 5,7$ & $10,8 \pm 6,3$ & $10,9 \pm 4,8$ & 0,879 \\
\hline \multicolumn{5}{|l|}{ Histopatoloji (n,\%) } \\
\hline Fibrotik & $52(12,5)$ & $38(10,2)$ & $14(34,1)$ & \multirow{6}{*}{$<0,01$} \\
\hline SCO & $99(23,9)$ & $91(24,4)$ & $8(19,5)$ & \\
\hline EMA & $81(19,6)$ & $76(20,4)$ & $5(12,1)$ & \\
\hline LMA & $52(12,5)$ & $42(11,2)$ & $10(24,3)$ & \\
\hline HS & $41(9,9)$ & $37(9,9)$ & $4(9,7)$ & \\
\hline NS & $88(21,3)$ & $88(23,6)$ & $0(0)$ & \\
\hline
\end{tabular}

SRR: sperm elde etme oranı, T: testosteron, E2: östradiol, FSH: foliküler stimüle edici hormon, LH: lüteinizan hormon, PRL: prolaktin, SCO: sertoli cell only sendromu, EMA: erken maturasyon aresti, LMA: geç maturasyon aresti,HS: hipospermatogenezis 
10 yıllık sürede KS'li infertil hastalarda mTESE deneyimimiz özetlenmiştir. KS'li hastalarda testiküler histopatolojinin çocukluk döneminden başlayarak bozulduğu bilinmektedir. ${ }^{[4]} \mathrm{Bu}$ bozulma erişkin yaşta NOA'ya sebep olarak bu hastalarda infertiliteye yol açmaktadır. KS hastalarda TESE ile ilk sperm eldesi 1996 yilında ve ilk canlı doğumda 1997 yılında sağlanmıştır. ${ }^{[9]}$ Literatürde KS'li hastalarda TESE'de sperm elde etme oranları, değişik çalışmalarda \%16 ile \%60 arasında değişmektedir. [6] Sabbaghian ve ark., 134 KS'li ve 537 normal karyotipli hastayı karşılaştırdıkları çalışmalarında, sperm elde etme oranını sırasıyla \%28,4 ve $\% 22,2$ saptamış ve bu farklılığın istatistiksel olarak anlamlı olmadığını raporlamışlardır. ${ }^{[10]}$ Bir başka çalışmada, Bakırcıoğlu ve ark., 106 KS'li ve 379 normal karyotipli hastanın TESE sonuçlarını karşılaştırmış ve KS'li hastalarda \%47, normal karyotipli hastalarda ise \%50 sperm elde etme oranlar1 bulmuşlardır. ${ }^{[11]} \mathrm{Bu}$ çalışmalardan farklı olarak, biz çalışmamızda KS'li hastalarda sperm elde etme oranını \%31,7 normal karyotipli hastalarda \%59,7 olarak bulduk. KS'li hastalarda sperm elde etme oranımız literatürle orantılı olmakla birlikte, normal karyotipli hastlarda sperm elde etme oranımız literatüre göre yüksektir. Bu yüksekliğin sebebinin, çalışmamızda sadece mikroskopik TESE tekniğinin kullanılmış olması ve TESE sonucunu olumsuz etkileyebilecek faktörlere sahip birçok hastanın çalışma dışı bırakılması olduğunu düşünmekteyiz.

Okada ve ark., yaptıkları çalışmada, hasta yaşının artmasının KS'li hastalarda mTESE başarısı için olumsuz bir faktör olduğunu bulmuş ve mTESE başarısı için 35 yaşı kritik yaş olarak saptamışlardır. ${ }^{[12]}$ Benzer şekilde Ferhi ve ark., KS'li hastalarda sadece hasta yaşının mTESE başarısı için prediktif faktör olduğunu ve mTESE başarısı için 32 yaşın kritik yaş olduğunu raporlamışlardır. ${ }^{[13]}$ Çalışmamızda, KS'li hastalarda ortalama yaş 30,8 yıl olarak saptanmış ve normal karyotipe sahip gruptan daha düşük bir ortalama yaş gözlenmesine rağmen bu farklılık istatistiksel olarak anlamlı olarak saptanmamıştır.

Çalışmamızda KS'li hastalarda mTESE öncesi androjen tedavisi uygulanmamıştır. KS'li hastalarda peripubertal dönemde normal pubertal gelişim için androjen yerine koyma tedavisinin faydalı etkileri olacağı gösterilmesine rağmen, bu tedavinin infertil hastalarda mTESE'den en az alt1 ay önce kesilmesi önerilmektedir. ${ }^{[6]}$ Alternatif terapötik seçenek olarak aromataz inhibitörleri (anastrozol or testolaktam), klomifen veya insan koryonik gonadotropin (hCG) hormonu kullanılabilmesine rağmen, bu konuda literatürde yeterli kontrollü çalışma yoktur.

KS'li hastalarda testiküler patolojideki bozulma, TESE'de sperm elde etme üzerine etkisi olan en önemli prediktif faktörlerden biridir. KS'li hastalarda testis histopatolojisi, sıklıkla skleroz, seminifer tübüllerde halizasyon ve Sertoli cell only olarak saptanmaktadır. ${ }^{[14]}$ Çalışmamızda literatür ile uyumlu olarak, KS'li hastalarda en sık görülen testiküler histopatoloji, tübüllerin fibrozisi olarak gözlenmiştir.

Çalışmamızda, KS’li hastalarda FSH düzeyi normal karyotipli hastalara göre yüksek saptanmıştır. FSH düzeyinin yüksek olmasının, TESE'de sperm bulma olasılığını istatistiksel olarak anlamlı olmasa da arttırdığını gösteren çalışmalar vardır. ${ }^{[5,15]}$ Yapılan bir çalışmada, NOA tanılı hastalar TESE operasyonu öncesi kan FSH düzeyleri <15, 15-30, 31-45, ve $>45 \mathrm{IU} / \mathrm{mL}$ olmak üzere dört ayrı gruba ayrılmış ve TESE sonrasında gruplar arasında sperm bulma oranları açısından anlamlı bir farklılık olmadığı görülmüştür. ${ }^{[16]}$ Dolayısıyla, serum FSH düzeyinin normal olması spermatozoa bulma ihtimalini arttırmayacağı gibi, yüksek FSH düzeyi de spermatozoa bulunmayacağı anlamına gelmemektedir.

Çalışmamıza dahil edilen hastaların ortalama inferilite sürelerinin uzun olduğu gözlenmiştir. Bu sürenin uzun olmasının sebebi, infertilite kliniğimize başvuran hasta popülasyonunun kırsal kesimden gelmesi ve sosyoekonomik düzeyinin düşük olmasına bağlı olarak sağlık kurumlarından uygun tedaviyi zamanında alma konusunda yetersiz kalmaları olabilir.

Çalışmamızın bazı limitasyonları vardır. Çalışmamızın ilk limitasyonu retrospektif olmasıdır. Çalışmamıza dahil edilen hastaların vücut kitle indeksi, sigara ve alkol kullanım özelliklerinin değerlendirilmemiş olması bir diğer limitasyondur. Çalışmamıza dahil edilen hastaların operasyonlarının tek cerrah tarafından yapılmamış olması ve hasta sayısının fazla olmasına rağmen çalışmamızın tek merkezli olması, limitasyon olarak kabul edilebilir. TESE'de elde edilen her sperm ICSI'da kullanılamamaktadır. Hastaların ICSI sonrası üreme sonuçlarının çalışmaya dahil edilmemesi çalışmamız için limitasyondur.

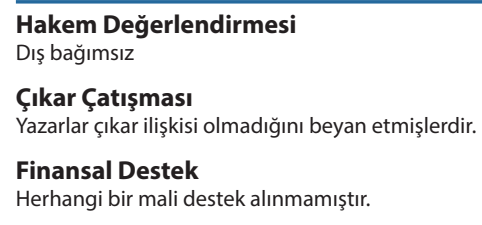

\section{KAYNAKLAR}

1. Corona G, Pizzocaro A, Lanfranco F, Garolla A, Pelliccione F, Vignozzi L, et al. On behalf of the Klinefelter Italian Group (KING). Sperm recovery and ICSI outcomes in Klinefelter syndrome: a systematic review and meta-analysis. Hum Reprod Update 2017;23:265-75. https://doi.org/10.1093/humupd/dmx008 
2. Majzoub A, Arafa M, Al Said S, Agarwal A, Seif A, Al Naimi A, El Bardisi H. Outcome of testicular sperm extraction in nonmosaic Klinefelter syndrome patients: what is the best approach? Andrologia 2016;48:171-6. https://doi.org/10.1111/and.12428

3. Ozveri H, Kayabasoglu F, Demirel C, Donmez E. Outcomes of micro-dissection TESE in patients with non-mosaic Klinefelter's syndrome without hormonal treatment. Int J Fertil Steril 2015;8:421-8.

4. Rohayem J, Fricke R, Czeloth K, Mallidis C, Wistuba J, Krallmann $\mathrm{C}$, et al. Age and markers of Leydig cell function, but not of Sertoli cell function predict the success of sperm retrieval in adolescents and adults with Klinefelter's syndrome. Andrology 2015;3:86875. https://doi.org/10.1111/andr.12067

5. Yucel C, Keskin MZ, Cakmak O, Ergani B, Kose C, Celik O, et al. Predictive value of pre-operative inflammation-based prognostic scores (neutrophil-to-lymphocyte ratio, platelet-to-lymphocyte ratio, and monocyte-to-eosinophil ratio) in testicular sperm extraction: a pilot study. Andrology 2017;5:1100-4. https://doi. org/10.1111/andr.12417

6. Aksglaede L, Juul A. Testicular function and fertility in men with Klinefelter syndrome: a review. Eur J Endocrinol 2013;168:67-76. https://doi.org/10.1530/EJE-12-0934

7. Schlegel PN. Testicular sperm extraction: microdissection improves sperm yield with minimal tissue excision. Hum Reprod 1999;14:131-5. https://doi.org/10.1093/humrep/14.1.131

8. Ustuner M, Yilmaz H, Yavuz U, Ciftci S, Saribacak A, Aynur BS, et al. Varicocele repair improves testicular histology in men with nonobstructive azoospermia. Biomed Res Int 2015:709452. https://doi.org/10.1155/2015/709452

9. Keskin MZ, Budak S, Köse C, Kaya ÖÖ, Özdemir TR, İlbey YÖ. Klinefelter sendromlu azospermik olgularda testiküler sperm ekstraksiyonu (TESE) başarısı için prediktif faktörler. Ege J Med 2016;55:51-4.
10. Sabbaghian M, Modarresi T, Hosseinifar H, Hosseini J, Farrahi F, Dadkhah F, et al. Comparison of sperm retrieval and intracytoplasmic sperm injection outcome in patients with and without Klinefelter syndrome. Urology 2014;83:107-10. https:// doi.org/10.1016/j.urology.2013.09.021

11. Bakircioglu ME, Ulug U, Erden HF, Tosun S, Bayram A, Ciray N, Bahceci M. Klinefelter syndrome: does it confer a bad prognosis in treatment of nonobstructive azoospermia? Fertil Steril 2011;95:1696-9. https://doi.org/10.1016/j. fertnstert.2011.01.005

12. Okada H, Goda K, Yamamoto Y, Sofikitis N, Miyagawa I, Mio Y, et al. Age as a limiting factor for successful sperm retrieval in patients with nonmosaic Klinefelter's syndrome. Fertil Steril 2005;84:16624. https://doi.org/10.1016/j.fertnstert.2005.05.053

13. Ferhi K, Avakian R, Griveau JF, Guille F. Age as only predictive factor for successful sperm recovery in patients with Klinefelter's syndrome. Andrologia 2009;41:84-7. https://doi.org/10.1111/ j.1439-0272.2008.00875.x

14. Koga M, Tsujimura A, Takeyama M, Kiuchi H, Takao T, Miyagawa $\mathrm{Y}$, et al. Clinical comparison of successful and failed microdissection testicular sperm extraction in patients with nonmosaic Klinefelter syndrome. Urology 2007;70:341-5. https://doi.org/10.1016/j. urology.2007.03.056

15. Turunc T, Gul U, Haydardedeoglu B, Bal N, Kuzgunbay B, Peskircioglu L, Ozkardes H. Conventional testicular sperm extraction combined with the microdissection technique in nonobstructive azoospermic patients: a prospective comparative study. Fertil Steril 2010;94:2157-60. https://doi.org/10.1016/j. fertnstert.2010.01.008

16. Ramasamy R, Lin K, Gosden LV, Rosenwaks Z, Palermo GD, Schlegel PN. High serum FSH levels in men with nonobstructive azoospermia does not affect success of microdissection testicular sperm extraction. Fertil Steril 2009;92:590-3. https://doi. org/10.1016/j.fertnstert.2008.07.1703 